\title{
Papers
}

\section{De novo expression of CD44 in prostate carcinoma is correlated with systemic dissemination of prostate cancer}

Valérie Paradis, Pascal Eschwège, Sylvain Loric, Fréderic Dumas, Nathalie Ba, Gérard Benoît, Alain Jardin, Pierre Bedossa

\begin{abstract}
Aims-To evaluate the role of CD44 in early steps in the development of prostate cancer, and to assess the biological significance of preneoplastic lesions in prostate cancer.

Methods-38 patients with clinically localised prostate cancer were studied. The standard form of CD44 (CD44H) and v6 isoform expressions were semiquantitatively evaluated on paraffin embedded tumour tissue by immunohistochemistry. Disseminated prostatic cells were detected by prostate specific membrane antigen reverse transcriptase polymerase chain reaction in the blood of each patient before radical prostatectomy.

Results-In normal or benign prostate glands, only basal cells showed CD44H and v6 labelling. Fourteen of the 38 prostate cancers $(37 \%)$ had CD $44 \mathrm{H}$ membranous staining of prostatic tumour cells. In 18 patients $(47 \%)$, circulating prostatic cells were detected in blood before surgery. Although no correlation between the expression of CD44 and the Gleason score or staging was observed, a significant correlation was found between the expression of CD44H by tumour cells and prostatic cell blood dissemination $(p=0.04)$. In 28 cases, foci of prostatic intraepithelial neoplasia were observed, and nine had CD44H immunostaining.

Conclusions-De novo expression of CD44 by prostatic tumour cells is associated with systemic dissemination of prostate cells independently of pathological criteria. (F Clin Pathol 1998;51:798-802)
\end{abstract}

Keywords: CD44; prostate cancer; prostatic intraepithelial neoplasia

Prostate cancer has become the most commonly diagnosed malignancy in Western countries. ${ }^{1}$ Although it usually develops in men over 65 years of age, the impact of this disease is significant. Indeed, approximately $50 \%$ of men with prostate cancer have clinically advanced disease at the time of diagnosis. ${ }^{2}$ Furthermore, among patients with organ confined prostate cancer, one third have micrometastatic disease at the time of surgery and will probably progress to metastatic disease. Since treatment differs according to the staging of the disease, it is important to detect patients who are at risk of systemic dissemination among those with clinically localised prostate cancer.

The natural history of and prognostic factors involved in prostate cancer are not clearly defined, and up to now there has been no screening method capable of accurately predicting the prognosis of localised prostate cancer. Since vascular invasion and blood spread of tumour cells represent preliminary steps in the metastatic process, detection of circulating epithelial cells in the blood could be an early marker of invasiveness. This can be achieved by reverse transcriptase polymerase chain reaction (RT-PCR) procedures which screen for epithelium specific mRNA species in blood samples. Using these methods, several studies have shown that the presence of epithelial cells in the blood of patients with cancer is a reliable biochemical marker of tumour aggressiveness. ${ }^{34}$ Indeed, we had previously shown, using prostate specific membrane antigen (PSMA) RT-PCR, that the presence of circulating prostatic cells before radical prostatectomy was correlated with biological recurrence of the cancer one year after surgery. ${ }^{5}$

Tumour cells express a wide variety of adhesion molecules which are implicated in the invasive and metastatic processes. Among these, CD44-a transmembrane glycoprotein acting as the main receptor for the glycosaminoglycan hyaluronan - has been viewed as a marker of aggressiveness in some cancers. ${ }^{67}$ CD 44 represents a large family of molecules which differ mainly in their primary structure, including a predominant form (CD44H, standard or haematopoietic form) and several variant isoforms resulting from alternative splicing of 10 exons (CD44 v1v10) of a single gene mapped on chromosome 11.89

Investigation of CD44 expression both in animal tumour models and human cancers has yielded conflicting results. Indeed, whereas CD44 expression is usually associated with the metastatic potential in human prostate tumour 


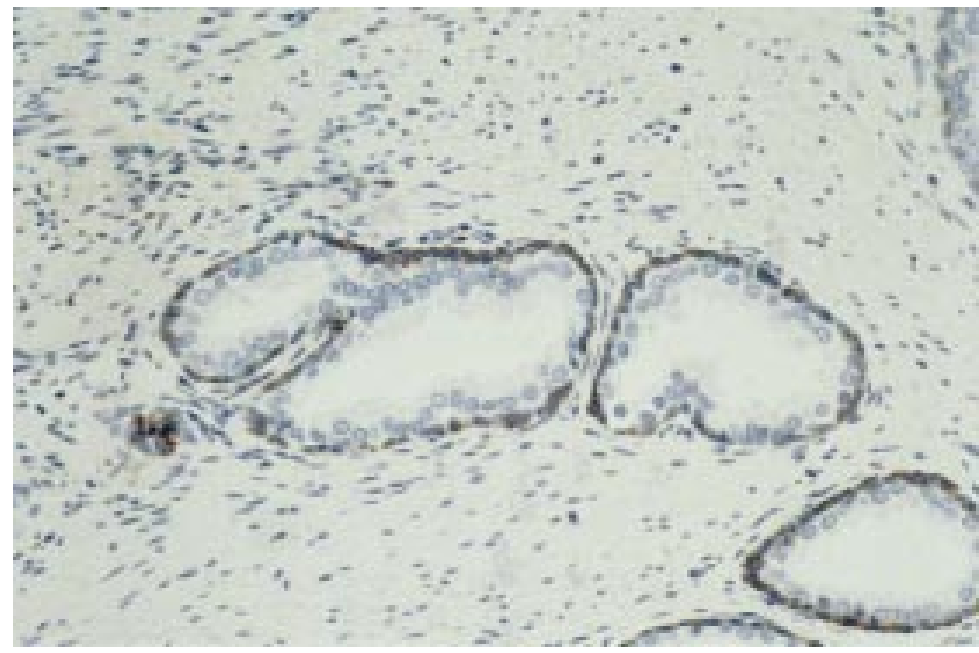

Figure 1 Immunohistochemical detection of CD44H in normal prostate tissue. Basal cells of normal prostatic glands are labelled. No staining of epithelial secretory cells is observed.

cell lines, ${ }^{10-13}$ downregulation of CD44 expression correlates with metastatic potential in the Dunning system of rat prostatic cancer sublines. ${ }^{14}$ Such discordant results were also shown in immunohistochemical studies investigating CD44 expression in human prostate cancers. ${ }^{15-18}$

Since modification of CD44 expression may be involved in tumour cell dissemination, we investigated in this study the expression of CD $44 \mathrm{H}$ and CD 44v6 by prostatic tumour cells in relation to the presence of prostate cell blood dissemination. In addition, in order to study the pathological progression of prostate cancer and to assess the biological significance of high grade prostatic intraepithelial neoplasia (PIN) - which are considered to be the main precursor lesions in prostate cancer-we also analysed CD44 expression patterns both in PIN and in adjacent cancer. ${ }^{19} 20$

\section{Methods}

PATIENTS

Thirty eight patients with clinically localised prostate cancer were included in the study. Mean age of the patients was 63 years (range 43 to 73). All cases were acinar carcinomas of the peripheral zone. None had lymph node metastasis. The diagnosis of prostate cancer was established histologically on a biopsy specimen. Radical prostatectomy and bilateral pelvic lymphadenectomy were performed for each patient. None had received preoperative hormone or radiation treatment. Prostate specimens were inked, fixed in formalin within 48 hours, totally embedded, and serially sliced perpendicular to the posterior surface of the gland.

For each specimen, a $5 \mu \mathrm{m}$ section was routinely processed and examined by two pathologists. The Gleason score system was used for the histological grade and the pathological stage was assigned using the TNM system (1997 revision). ${ }^{21}$ The presence of high grade PIN foci was reported systematically. As control, we used three histologically normal prostates obtained from cystoprostatectomies for bladder carcinomas.
For each patient, the biological recurrence was evaluated by the determination of the serum ultrasensitive PSA level.

IMMUNOHISTOCHEMICAL STUDY

For each case, three samples of the prostate cancer were selected. They were chosen because they presented the most commonly observed histological pattern throughout the entire gland. The immunohistochemical procedure was performed on paraffin embedded 5 $\mu \mathrm{m}$ sections using an automated immunostainer (Techmate 500, Dako) with the avidinbiotin-peroxidase method. Mouse monoclonal antisera to $\mathrm{CD} 44 \mathrm{H}$ and CD44v6 (R\&D Systems) were used at a 1:1200 dilution with microwave pretreatment. As negative controls, we used normal sheep, phosphate buffered saline, or irrelevant antibodies instead of primary antibodies.

Immunostaining was independently evaluated by two pathologists. Discordancies were resolved at a combined session. Positive samples were defined as cases showing a frank membranous staining pattern of epithelial tumour cells. When staining was observed, it was semiquantitatively assessed as focal (less than $20 \%$ of labelled tumour tissue) or diffuse (more than $20 \%$ of labelled tumour glands).

DETECTION OF CIRCULATING PROSTATE CELLS BY RT-PCR

Blood sample specimens were collected one day before radical prostatectomy. Venous blood $(4 \times 5 \mathrm{ml})$ was collected in EDTA treated tubes, placed at $4^{\circ} \mathrm{C}$, and processed within three hours. Blood samples were diluted in 2 volumes of ammonium chloride, $9 \mathrm{~g} /$ litre, then shaken overnight at $4^{\circ} \mathrm{C}$. After centrifugation at $1000 \mathrm{~g}$ for 20 minutes, the supernatant was removed before RNA extraction. The RNA pellet obtained after ethanol/sodium acetate precipitation was dried under vacuum and dissolved in $50 \mu \mathrm{l}$ RNAse-free water. PSMA RT-PCR was performed as previously described. ${ }^{22}$ Briefly, RNA samples were reverse transcribed in cDNA with downstream PSMA oligonucleotide as primer. Then $1 \mu \mathrm{l}$ of cDNA was amplified by PCR with outer PSMA primers in an MJResearch DNA thermal cycler (TechGen) according to the following program parameters: $94^{\circ} \mathrm{C}$ for one minute (two minutes for the first cycle), $62^{\circ} \mathrm{C}$ for one minute, and $72^{\circ} \mathrm{C}$ for one minute $(10$ minutes for the last cycle) for 25 cycles. A $3 \mu 1$ aliquot of amplimers was amplified in a nested fashion through 25 new cycles with a PSMA inner couple of primers. To assess the integrity of the different RNAs extracted from blood samples, a region of $\beta$ globin was amplified in the same conditions as PSMA except for the hybridisation temperature $\left(58^{\circ} \mathrm{C}\right)$ and the number of cycles (35 cycles). PCR products were electrophoresed on a $2 \%$ agarose gel (FMC), stained with ethidium bromide, and visualised under ultraviolet light.

STATISTICS

Distributions between groups were compared using the $\chi^{2}$ test or the Fisher exact test for 


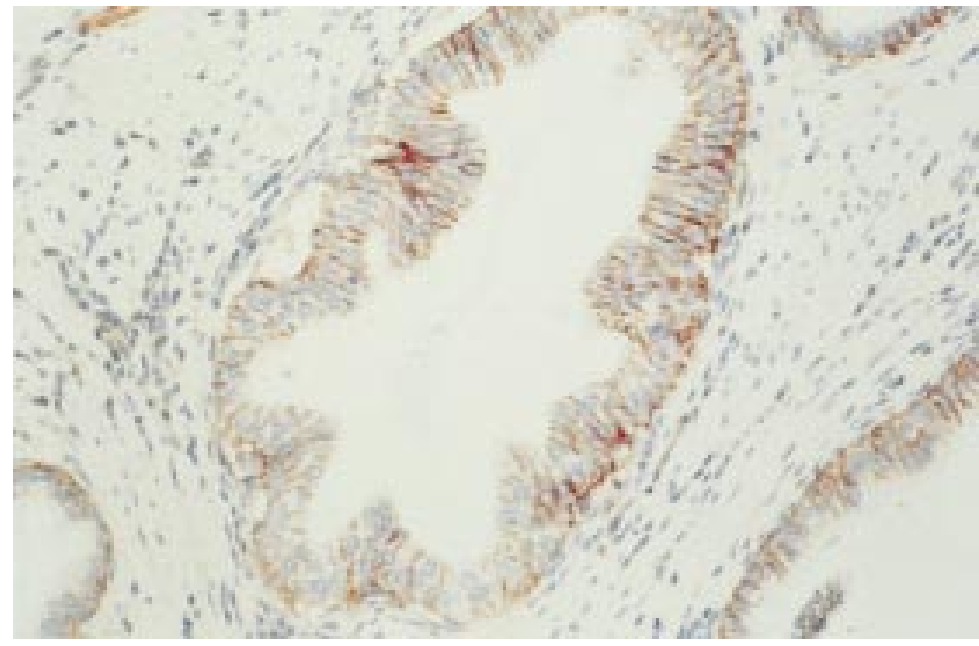

Figure 2 Immunohistochemical detection of CD44H in prostatic intraepithelial neoplasia. Epithelial secretory cells of glands showing prostatic intraepithelial neoplasia show strong CD44 immunostaining of the basolateral cell membrane. Lymphocytes are also labelled in the connective tissue.

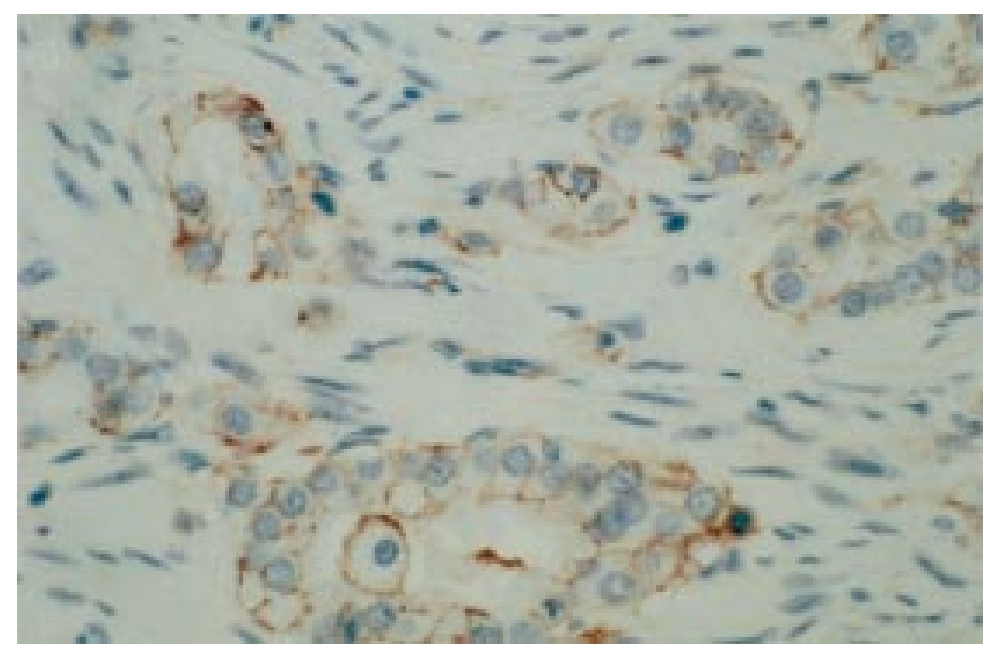

Figure 3 Immunohistochemical detection of CD44H in prostate cancer. A group of prostatic tumour glands invading the connective tissue are labelled. Tumour cells show strong and continuous membranous immunostaining.

qualitative data, and the Student $t$ test for quantitative data. The $\mathrm{p}$ value of 0.05 was chosen as the significance level. In the analysis of disease progression or survival, patients who had a biological recurrence or who died during follow up were classified as failures, and patients who did not have a recurrence during the study were coded as censored. Progressionfree survival was evaluated using the KaplanMeier method and the log rank test.

\section{Results}

PATIENTS

All prostate cancers were acinar adenocarcinomas, and the mean (SD) Gleason score was 6.9 (0.7). Nine of them were low grade (Gleason $<7$ ) and 29 were high grade (Gleason $\geqslant 7$ ). Twenty nine patients were diagnosed as being at pathological stage pT2, and nine were at pT3.

IMMUNOSTAINING OF CD44

In normal prostate tissue, $\mathrm{CD} 44 \mathrm{H}$ labelling of basal cells was always observed, whereas normal epithelial secretory cells were not
Table 1 Distribution of prostate carcinomas according to CD44 expression and presence of circulating prostate cells (38 cases)

\begin{tabular}{lll}
\hline & \multicolumn{2}{l}{ Circulating prostate cells } \\
\cline { 2 - 3 } CD44 immunostaining & Present & Absent \\
\hline Positive & 10 & 4 \\
Negative & 8 & 16 \\
\hline
\end{tabular}

labelled (fig 1). By contrast, in 14 of the 38 cases studied by immunohistochemistry (37\%), malignant epithelial cells also showed $\mathrm{CD} 44 \mathrm{H}$ immunolabelling. In all positive cases, staining was restricted to the basolateral membrane of tumour cells (fig 2). Four cases were graded as having focal positivity and 10 cases as having diffuse immunostaining. No difference in staining was detected when carcinomatous glands localised in the centre of the cancer were compared with glands located in the leading edges of the tumour. In normal prostate tissue, CD44v6 immunostaining was faint, merely restricted to the basal cells of the large prostatic ducts. In only two patients was membranous labelling observed in the malignant epithelial cells.

The presence of high grade PIN foci adjacent to the cancer was reported in 28 cases $(74 \%)$, including 11 cases among the 14 cancers showing $\mathrm{CD} 44 \mathrm{H}$ staining. In nine of the 28 cases $(32 \%)$, the epithelial luminal cells of the PIN foci also showed CD44H membranous labelling (fig 3). In all these cases, epithelial cells of invasive carcinoma also showed $\mathrm{CD} 44 \mathrm{H}$ immunostaining. In contrast, no staining was observed in the PIN foci localised around the cancers negative for CD44H. Furthermore, PIN foci were never labelled by CD44v6, even in the two positive cancers.

CORRELATIONS WITH PATHOBIOLOGICAL DATA Among the 38 patients, 18 had circulating prostatic cells in the blood, as shown by the detection of PSMA mRNA by RT-PCR. CD44H expression in prostate cancer was correlated with the presence of prostate cells in the blood, as detected by RT-PCR. Ten of the 14 patients with CD44H labelling in prostate cancer were PSMA RT-PCR positive, whereas only eight of the 24 patients who did not have focal or diffuse $\mathrm{CD} 44 \mathrm{H}$ immunolabelling in prostate cancer were PSMA RT-PCR positive $\left(\chi^{2}=5.1\right.$; Fisher's exact test, $\mathrm{p}=0.01$ ) (table 1 ).

No correlation was observed between the presence of $\mathrm{CD} 44 \mathrm{H}$ in prostate cancer and the pathological stage or the Gleason grade. In the group of 14 patients with de novo expression of $\mathrm{CD} 44 \mathrm{H}$, two had a low Gleason score $(<7)$ and 12 had a high Gleason score $(\geqslant 7)$. The distribution was not significantly different in the 24 cases without $\mathrm{CD} 44 \mathrm{H}$ expression, where seven were low grade and 17 were high grade $\left(\chi^{2}=2.12, \mathrm{NS}\right)$. In the group of patients with $\mathrm{CD} 44 \mathrm{H}$ positive prostate cancers, 12 of the 14 cases were pT2, and two were pT3. In the group of patients without $\mathrm{CD} 44 \mathrm{H}$ positive prostate cancers, 17 cases were pT2 $v$ seven cases staged pT3. Distribution was not statistically different $\left(\chi^{2}=1.1, \mathrm{NS}\right)$. 
The two cases with CD44v6 expression also showed CD $44 \mathrm{H}$ immunostaining. In these two patients, circulating blood epithelial cells were detected. Patients had a high Gleason grade ${ }^{7}$ and both were staged pT3.

DISEASE PROGRESSION

The mean follow up was 514 days (176 to 883 days). During the follow up, one patient died and 10 had a biological recurrence, as assessed by the serum PSA level measured one year after radical prostatectomy. Staging of the disease was the only variable associated with disease progression (log rank test, $\mathrm{p}=0.05$ ).

\section{Discussion}

The natural history of prostate cancer is not yet clearly defined, and the behaviour of this cancer varies from patient to patient. To make an early assessment of the aggressiveness of the cancer, it is crucial to develop new biological or molecular markers. Since vascular migration of tumour cells represents the first step in the initiation of metastasis, the detection of epithelial cells in the blood by RT-PCR appears to be a logical end point to assess the early mechanism of tumour invasion.

Though it was initially described as a molecule that was mainly involved in lymphocyte homing, it is now evident that CD44 also plays a major role in tumour progression and metastasis formation. ${ }^{73}$ However, analysis of the expression of $\mathrm{CD} 44 \mathrm{H}$ and its variant isoforms has yielded divergent results, depending on the type of normal and malignant human tissues studied. In prostate, there is strong evidence that CD44 expression is restricted to basal cells of normal glands. ${ }^{11}{ }^{17}$ In tumour cell lines, in vitro studies have shown upregulation of CD44 expression. ${ }^{10-13}$ In human tumours, results of immunohistochemical studies are more conflicting. Whereas some studies suggest downregulation of CD44 expression by tumour cells, ${ }^{17}{ }^{24}$ especially in high grade carcinomas, we and others have shown upregulation of CD44 expression by tumour cells. ${ }^{11} 1618$ The latter results are more in accordance with experimental data showing that basal cell markers are expressed by carcinomatous cells and not by normal epithelial secretory cells. ${ }^{25}$ These newly expressed markers could confer growth and survival advantages upon these tumour cells.

It is of note that most immunohistochemical studies have correlated CD44 expression with late events in cancer progression, such as the occurrence of metastases. ${ }^{16}{ }^{17}$ Since CD 44 is a key molecule involved in the cell-matrix adhesion process, we chose to study CD44 expression in correlation with an earlier step of the tumour process. We therefore correlated the de novo expression of CD44 in clinically localised prostate cancer with the blood dissemination of prostatic cells in the absence of overt metastases. We showed that the expression of $\mathrm{CD} 44 \mathrm{H}$ by tumour cells is correlated with the presence of circulating prostatic cells, suggesting that CD44 molecules may help cause the epithelial tumour cells to enter the bloodstream. It is noteworthy that E-cadherin, another major cell-cell adhesion molecule, is also involved in systemic dissemination. Indeed we, like others, have previously shown that membranous E-cadherin immunostaining is lost when prostate cells disseminate in prostate cancer. $^{5}$

Expression of CD44 variant isoforms had been previously correlated with tumour progression in various cancers, including colorectal, mammary, and gastric cancers. ${ }^{76-29}$ Furthermore, in some cancers such as clear cell carcinomas of the kidney, expression of CD44 isoforms increased during tumour differentiation from the G1 to the G3 stages. ${ }^{30}$ Surprisingly, in our study, no correlation was found between CD44 expression or circulating prostate cells and the Gleason score or the stage of the disease, which are the main histoprognostic factors. However, most of the prostate cancers included in the present study had a low or medium Gleason score $(<7)$, and such analysis should be reassessed in a larger group, including patients with higher scores. Since CD44 expression is found even in cases with low grade and stage, it can also be presumed that the initial step of the metastatic process (that is, entering of tumour cells into the bloodstream) is not associated with any of the classical pathologic features of aggressiveness and can occur very early in the carcinomatous process.

Interestingly, no correlation was found between CD44 de novo expression by tumour cells and biological recurrence. This suggests that other factors are required for the circulating cells to induce local recurrence or subsequent metastasis development.

In this study, we also examined the expression of CD44 in high grade PIN foci adjacent to the cancer. PIN is described as cytologically atypical cells within a normal duct or acinar outline. There is evidence from morphological and immunohistochemical studies to suggest that high grade PIN represents a precursor of prostate cancer. ${ }^{19}$ We found that the PIN foci and the adjacent cancer share a similar pattern of expression of CD44H. These data show that epithelial cells of high grade PIN have already acquired some phenotypic markers of invasive tumour cells and thus may be considered premalignant lesions. The demonstration of de novo CD44 expression in PIN lesions deserves further comment. It is generally agreed that tumour dissemination cannot be observed at the stage of in situ carcinoma. Our results suggest that factors other than CD44 upregulation are required for a tumour cell to achieve an invasive phenotype.

The mechanism by which a tumour cell invades the surrounding structure is poorly understood. Several in vitro models suggest that extracellular matrix composition might regulate cell invasion, and that hyaluronan might facilitate the invasive behaviour of tumour cells. Since CD44 is a major hyaluronan receptor, its de novo expression might play a role in hyaluronan mediated facilitation of invasion. Indeed, the blocking of CD 44 with a specific antibody in vitro results in significant reduction in invasion of tumour cells. ${ }^{31}$ Complementary immunohistochemical studies of 
the composition of the extracellular matrix in prostate cancers could help to confirm the role of this CD44-hyaluronan interaction.

In conclusion, we have shown in this study that de novo CD44 expression occurs in a subset of prostate cancers in correlation with systemic spreading of prostate cells. The early involvement of CD44 in prostate carcinogenesis is reinforced by the demonstration of positive CD44 immunostaining in preneoplastic lesions.

1 Boring CC, Squires TS, Tong T, et al. Cancer statistics. $C A$ Cancer F Clin 1994;44:7-26.

2 Rosen MA, Goldstone L, Lapin S, et al. Frequency and location of extracapsular extension and positive surgical margins in radical prostatectomy. F Urol 1992;148:331-7.

3 Matsumara M, Niwa $\mathrm{Y}$, Kato $\mathrm{N}$, et al. Detection of alfa-foetoprotein mRNA, an indicator of hematogenous spreading of hepatocellular carcinoma, in the circulation: a possible predictor of metastatic hepatocellular carcinoma. Hepatology 1994;20:1418-25.

4 Jaakkola S, Vornanen T, Leinonen J, et al. Detection of prostatic cells in peripheral blood: correlation with serum concentration of prostate-specific antigen. Clin Chem 1995; 412:182-6.

5 Loric S, Eschwège, Dumas F. Inverse correlation of E-cadherin expression with prostate epithelial cell microdissemination in patients with prostate confined adenocarcinoma. F Urol 1997;157:367.

6 Günthert U, Hofmann M, Rudy W, et al. A new variant of glycoprotein CD44 confers metastatic potential to rat carcinoma cells. Cell 1991;65:13-24.

7 Matsumara Y, Tarin D. Significance of CD44 gene products for cancer diagnosis and disease evaluation. Lancet 1992;340:1053-8.

8 Screaton GR, Bell MV, Jackson DG, et al. Genomic structure of DNA encoding the lymphocyte homing receptor CD44 reveals at least 12 alternatively spliced exons. Proc Natl Acad Sci USA 1992;89:12160-4.

9 Jackson DG, Buckley L, Bell JI. Multiple variants of the human lymphocyte homing receptor CD44 generated by insertions at a single site in the extracellular domain. 7 Biol Chem 1992;367:4732-9.

10 Liu AY. Expression of CD44 in prostate cancer cells. Cancer Lett 1994;76:63-9.

11 Stevens JF, Palechek PL, Griebling TL, et al. Expression of CD 44 isoforms in human prostate tumor cell lines. Prostate 1996;28:153-61.

12 Welsh CF, Zhu D, Bourguignon LYW. Interaction of CD44 variant isoforms with hyaluronic acid and the cytoskeleton in human prostate cancer cells. F Cell Physiol 1995;164 605-12.

13 Lokeshwar BL, Lokeshwar VB, Block NL. Expression of CD44 in prostate cancer cells: association with cell proliferation and invasive potential. Anticancer Res 1995;15: 1191-8.
14 Gao AC, Lou W, Dong JT, et al. CD44 is a metastasis suppressor gene for prostatic cancer located on human chromosome 11p13. Cancer Res 1997;57:846-9.

15 Kallakury BVS, Yang F, Figge J, et al. Decreased levels of CD44 protein and mRNA in prostate carcinoma: correlation with tumor grade and ploidy. Cancer 1996;78:1461-9.

16 Nagabhushan M, Pretlow TG, Guo YJ, et al. Altered expression of CD44 in human prostate cancer during progression. Am f Clin Pathol 1996;106:647-51.

17 Griebling TL, Palechek PL, Cohen MB. Immunohistochemical and soluble expression of CD44 in primary and metastatic human prostate cancers. Int f Oncol 1997;10: 697-702.

18 Zhang XH, Sakamoto H, Takenaka I. Accumulation of p53 and expression of CD44 in human prostatic cancer and and expression of CD44 in human prostatic cancer and benign prostatic hyperplasia:

19 Bostwick DG. High grade prostatic intraepithelial neoplasia: the most likely precursor of prostate cancer. Cancer 1995;75:1823-36.

20 McNeal JE, Bostwick DG. Intraductal dysplasia: a premalignant lesion of prostate. Hum Pathol 1986;17:64-71.

21 Blute ML, Bostwick DG, Seay TM, et al. Pathologic classification of prostate carcinoma. The impact of margin status. Cancer 1998;82:902-8.

22 Loric S, Dumas F, Eschwege P, et al. Enhanced detection of hematogenous circulating prostatic cells in patients with prostate adenocarcinoma using prostate specific antigen
(PSM)-based nested reverse transcription polymerase chain reaction assay. Clin Chem 1995;41:1698-704.

23 Jalkanen S, Bargatze RF, Toyos JDL, et al. Lymphocyte recognition of host endothelium: antibodies to distinct epitopes of an 85-95 kD glycoprotein antigen differentially inhibit lymphocyte cells. $\mathscr{F}$ Cell Biol 1987;105:983-90.

24 Marzo AM, Bradshaw C, Sauvageot J, et al. CD44 and CD44v6 downregulation in clinical prostatic carcinoma: relation to Gleason grade and cytoarchitecture. Prostate 1998;34:162-8.

25 Liu AY, True LD, Latray L, et al. Cell-cell interaction in prostate gene regulation and cytodifferentiation. Proc Nat Acad Sci USA 1997;94:10705-10.

26 Tanabe KK, Ellis LM, Saya H. Expression of CD44R adhesion molecule in colon carcinomas and metastases. Lancet 1993;341:725-6.

27 Wielenga VJM, Heider KH, Offerhaus GJA, et al. Expression of CD44 variant proteins in human colorectal cancer is related to tumor progression. Cancer Res 1993;53:47546.

28 Mayer B, Jauch KW, Günthert U, et al. De novo expression of CD44 and survival in gastric cancer. Lancet 1993;342: 1019-22.

29 Fujita N, Yaegashi N, Ide Y, et al. Expression of CD44 in normal human versus tumor endometrial tissues: possible implication of reduced expression of CD44 in lymphvascular space involvement of cancer cells. Cancer Res vascular space inv

30 Terpe HJ, Störkel S, Zimmer U, et al. Expression of CD44 isoforms in renal cell tumors: positive correlation to tumor differentiation. Am F Pathol 1996;148:453-63.

31 Radotra B, McCormick D. Glioma invasion in vitro is mediated by CD44-hyaluronan interactions. F Pathol 1997;181: $434-8$. 